
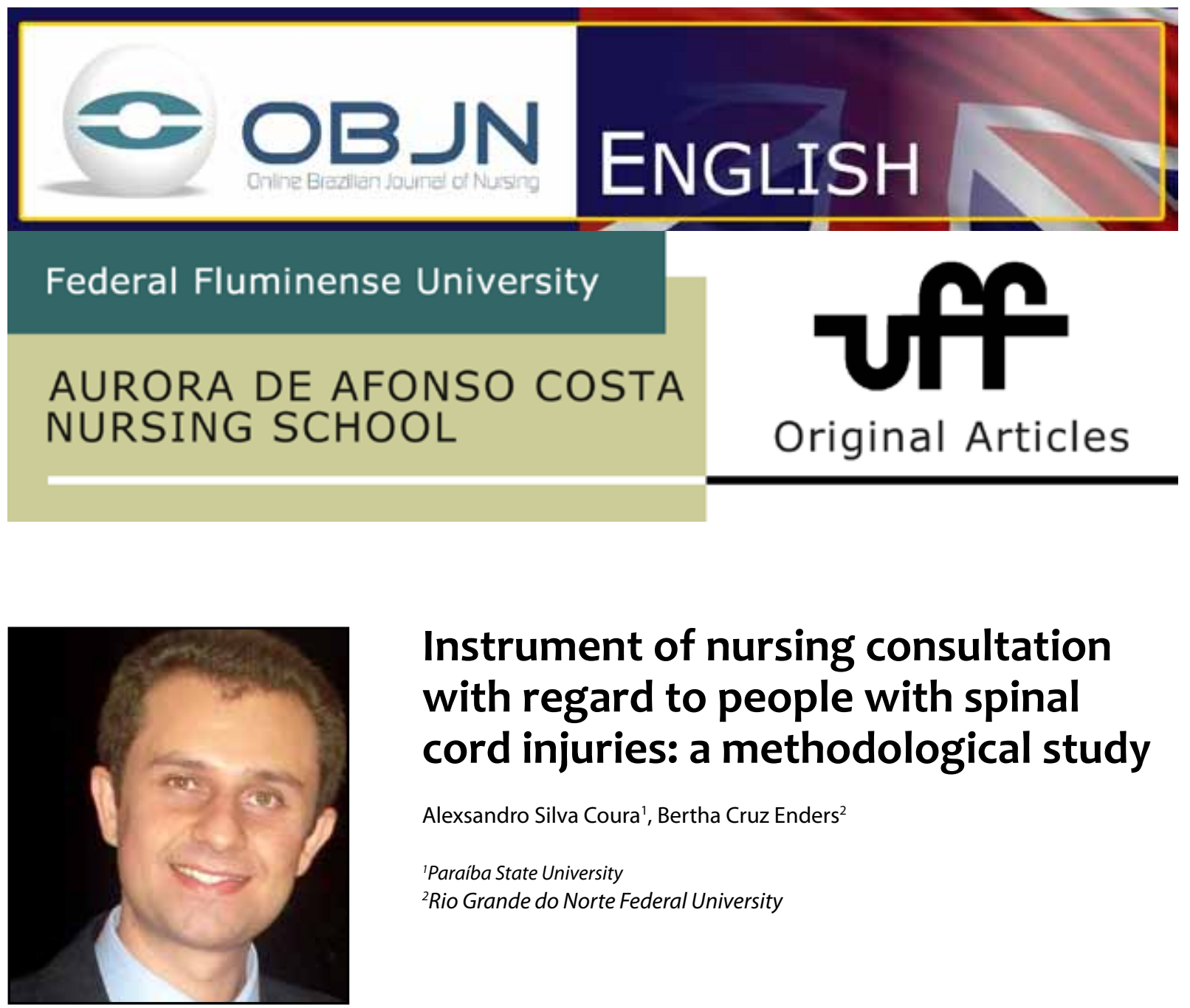

\title{
Instrument of nursing consultation with regard to people with spinal cord injuries: a methodological study
}

\author{
Alexsandro Silva Coura', Bertha Cruz Enders² \\ 'Paraíba State University \\ ${ }^{2}$ Rio Grande do Norte Federal University
}

\begin{abstract}
Problem: Spinal cord injury is a public health issue, and a specific instrument to guide nursing consultations for those affected does not exist.

Aim: To develop and validate an Instrument of Nursing Consultation for Home Visits to People with Spinal Cord Injuries (INCEVDOP-LM, in Portuguese), based on the Self-Care Deficit Theory.

Method:This is a study of methodological development, created in the Family Health Units of the city of Natal, with nurses, judging nurses, and people with spinal cord injuries, between 2012 and 2013. There will be two phases: I - Identification of the necessities of self-care through a Socio-Demographic Questionnaire and a Scale of Evaluation of Competency to Self-Care; II - Development and validation of INCEVDOP-LM based on presentation, content and reliability (the first two criteria will be based on the opinion from judging nurses and a Kappa test, and the last criterion will be examined by the Cronbach's Alpha test). Consultations using or not using the INCEVDOP-LM will be filmed. These recordings will be analyzed using a scale of evaluation and Chi-square and Fisher tests.
\end{abstract}

Descriptors: Nursing; Spinal Cord Injuries; Self Care; House Calls; Validation Studies. 


\section{PROBLEM SITUATION AND ITS SIGNIFICANCE}

The incidence of spinal cord injuries $(\mathrm{SCl})$ is becoming a significant public health issue due to the rise in violent situations such as vehicle accidents and gun crimes ${ }^{(1)}$. In the United States there is an estimated incidence of 11,000 cases of $\mathrm{SCl}$ per year. In Brazil, it is believed that there are 10,000 new cases annually ${ }^{(2)}$.

Any damage to the spinal cord can generate motor, sensorial, metabolic and sexual problems, as well as a dysfunction of vesical/ intestinal sphincters ${ }^{(1)}$.

When considering those people with $\mathrm{SCl}$ who suffer locomotion difficulties and are in a self-care situation ${ }^{(1)}$, there is a need to stimulate them daily. Consequently, one important strategy is home visits by nurses. To have a satisfactory home visit, it is necessary that the nursing consultation is of a good standard, aiming to identify health problems and to intervene in such a way as to promote and protect the health status of the subjects, their families and the community in which they live, and to help them recuperate. Within this context, this study is justified, as it is not known if there are any specific instruments to guide home nursing consultations in terms of these requirements. The absence of systematization in this process, mediated through an instrument that focuses on the individual and his/her family, as it is listed by the Family Health Brazilian National Strategy, can harm the assisting services and can create difficulties in terms of promoting self-care.

The relevance of this research is based on its potential social impact, leading to the development of technology that will contribute to an improvement in nursing consultation and to improving the health of patients with $\mathrm{SCl}$. This study will improve nursing intervention in basic care.
AIMS

General: To develop and validate an Instrument of Nursing Consultation for Home Visit to People with Spinal Cord Injuries (INCEVDOP-LM, in Portuguese), based on the Self-Care Deficit Theory.

Specific: To identify the self-care needs of people with SCl; to build the INCEVDOP-LM; to validate the presentation, the content and the reliability of INCEVDOP-LM and; to evaluate the INCEVDOP-LM in terms of guiding the actions during its application as part of nursing consultation with people with $\mathrm{SCl}$ in their homes.

\section{HYPOTHESIS}

The levels of validation of INCEVDOP-LM are satisfactory if Kappa $>0.75$, the frequency of positive answers $\geq 90 \%$ with $p<0.05$, and if Cronbach's Alpha $>0.70$.

\section{METHOD}

This is a study of a methodological development ${ }^{(3)}$, that was performed with the help of judging nurses, people with $\mathrm{SCl}$, and nurses from the Family Health Units (USF, in Portuguese) from the city of Natal, between 2012 and 2013. According to Image 1, there will be two stages: the first will identify the need for self-care on the part of people with $\mathrm{SCl}$, and the second will develop and validate INCEVDOP-LM. In the first, we will run a census of the people with $\mathrm{SCl}$ residing in Natal. In the second, the sample will be by convenience as, due to the characteristics of this study, it is important to have some homogeneity in terms of the participants, and an acceptable quality in terms of the answers regarding the pertinence of the instrument to be developed ${ }^{(3)}$. 
Image 1 - Flowchart of the stages of the study. Natal, Brazil, 2012

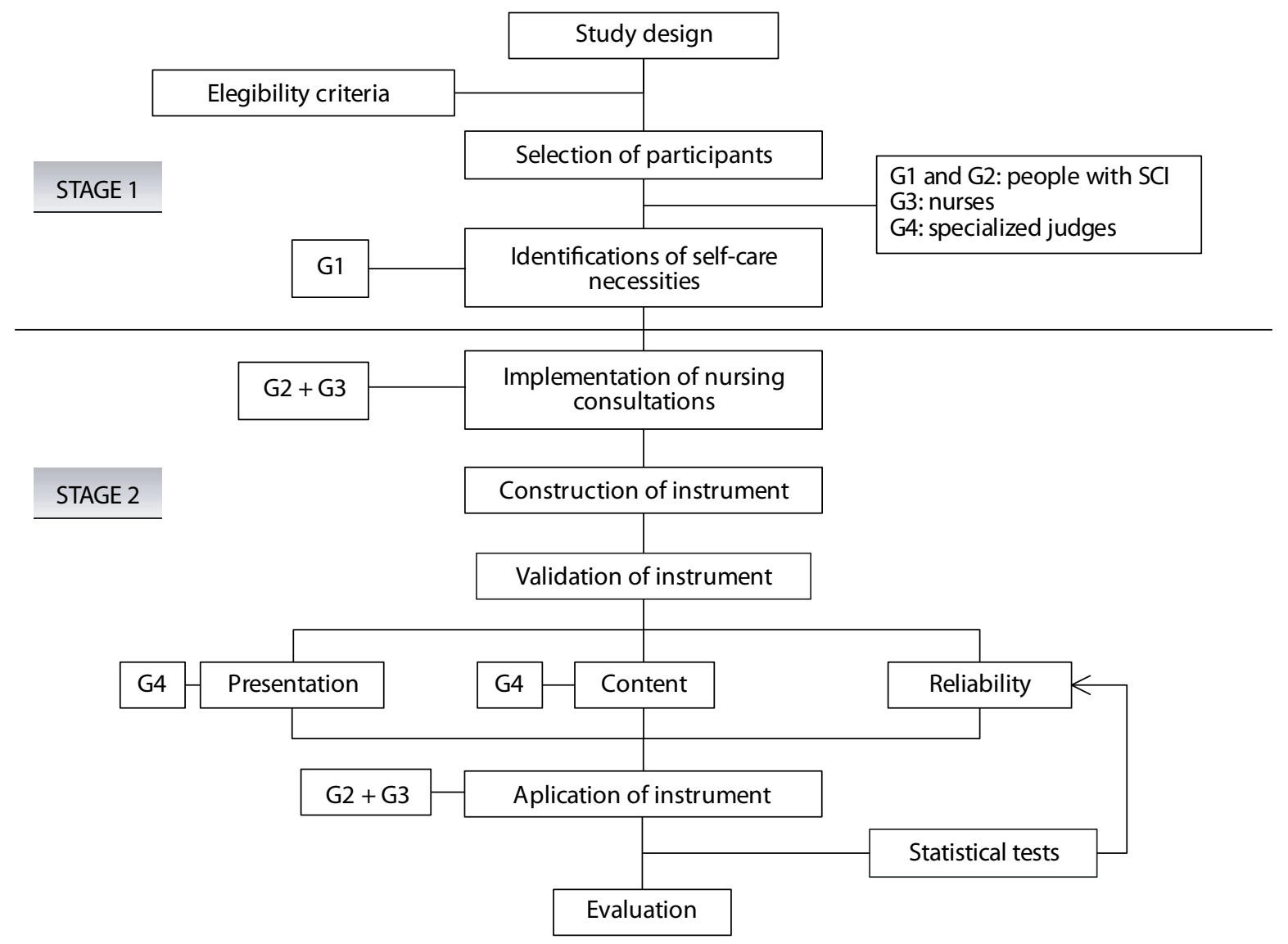

There will be four groups of patients: First stage - $\mathrm{G} 1$ : adults with $\mathrm{SCl}$, diagnosed by a specialist, with paraplegia or tetraplegia, 18 years old or older; Second stage - $\mathrm{G} 2$ : 30 adults with $\mathrm{SCl}$, following the same criteria of inclusion as with G1; G3: 30 nurses who have worked in USF for more than two years; G4: six judging nurses with $\mathrm{PhDs}$, with some experience in the area of technology development. The excluding criteria will be presenting apparently impaired cognitive functions. For data collection in terms of the first group, we will have some home visits and apply a Socio-demographic Questionnaire and a Scale of Evaluation of Competency to Self-Care. In terms of the second group, the data collection will be divided in five parts: I - Implementation and recording of consultations by the nurses at the home of 30 people with SCl; II - Construction of the INCEVDOP-LM, according to the Self-Care Deficit Theory; III-Validation of the INCEVDOP-LM based on presentation, content and reliability. The first two will be developed according to the opinion of the judges and Kappa tests, and the last using Cronbach's Alpha ${ }^{(3)}$; IV - Application of INCEVDOP-LM: the nurses will implement home consultations of 30 people with $\mathrm{SCl}$ using the instrument. The consultation will be video recorded; $V$ - Evaluation of INCEVDOP-LM: the video recordings will be analyzed in terms of an evaluation scale of the actions performed by the nurses, and by the Chi-square and Fisher tests, calculated in SPSS ${ }^{(3)}$. This project was approved by the Ethics in Research Committee of Rio Grande do Norte Federal University, under protocol CAAE 0248.0.051.000-11. 


\section{REFERENCES}

1. Vasconcelos AS, França ISX, Coura AS, Sousa FS, Souto RQ, Cartaxo HGO. Nursing interventions on the needs of people with spinal cord injury: an integrative review. Online Braz J Nurs [Internet]. 2010 [Cited 2012 Apr 10]; 9(2). Available from: http://www.objnursing.uff.br/index.php/ nursing/article/view/j.1676-4285.2010.3000/674

2. Campos MF, Ribeiro AT, Listik S, Pereira CAB, Andrade Sobrinho J, Rapoport A. Epidemiologia do traumatismo da coluna vertebral. Rev Col Bras Cir. 2009; 35(2):88-93.

3. Field A. Descobrindo a Estatística usando o SPSS. 2. ed. Porto Alegre: Artmed; 2009.
Information about the project: $\mathrm{PhD}$ Thesis Project, from the Post-Graduation Program in Nursing, Rio Grande do Norte Federal University.

Date of qualification: Sept/26/2012.

Examiners: Ana Luisa Brandão de Carvalho Lira; Bertha Cruz Enders; Inacia Sátiro Xavier de França; Lorita Marlena Freitag Pagliuca; Rejane Maria Paiva de Menezes.

Scholarship: CNPq.

Participation of the authors

Alexsandro Silva Coura - Concept, design, writing, critical review and final approval.

Bertha Cruz Enders - Concept, design, writing, critical review and final approval.

Received: $21 / 11 / 2012$

Revised: 09/06/2013

Approved: $17 / 06 / 2013$ 